MARKETING AND BRANDING
RESEARCH $\begin{gathered}\text { INDUSTRIAL } \\ \text { MANAGEMENT } \\ \text { INSTITUTE }\end{gathered}$

\title{
Analyses of the role of government, industry, and the culture of resistive economy in people's attitude to purchase the Iranian brand products
}

\author{
Atefeh Shiravi Khozani $^{{ }^{*}}$, Hossein Rezaei Dolatabadi ${ }^{2}$ \\ ${ }^{1}$ Department of Economics and Administrative Sciences, Isfahan University, Isfahan, Iran \\ 2 Isfahan University, Isfahan, IRAN
}

\begin{abstract}
Keywords:

Resistive economy, attitude to purchase, brand, role of government

Correspondence:

atefeh.shiravi123@gmail.com

This study aimed to examine the role of government, industry, and the culture of resistive economy in the attitude of people to buy products with Iranian brand to help manufacturers to produce high quality goods. Accordingly, to conduct the research, a conceptual model was developed and an analytical survey method was used. The population of the study was the appliance manufacturers participating in the exhibition in Isfahan in August 1393, of which 93 were selected randomly. Data obtained from a questionnaire was analyzed with SPSS 22 software and Smart PLS 2.0. The results showed that the government, industry, economy, and culture of resistance had a significant positive impact on people's attitude to buy products with Iranian brand.
\end{abstract}

\section{Introduction}

In today's open markets throughout the world, products and services have their markets for clients and customers. However, even when products are superior in terms of quality or price than the host country, the possibility of doing business successfully in foreign markets can be difficult for some reasons unrelated to the provisions and regulations (Klein, Ettenson, \& Morris, 1998; Nijssen \& Douglas, 2004). Orientation to the origin of products creates a challenge for marketers and this increases the complexity of international marketing and provides an opportunity for local producers to keep their customers. But there are different kinds of purchasers and recognizing the homogeneous segments of the market provides 
appropriate strategies (Mortazavi, Kaffashpur, \& Arjmandi Nezhad, 2010). Consumer ethnocentrism is considered as a strong intangible barrier to international trade (John \& Brady, 2011; Shankarmahesh, 2006).

Unfortunately, though Iranian products have high quality, countries like China, Turkey, and Malaysia have severely affected the domestic market share. It is something that not only makes the situation difficult for the domestic industry, but also affects the social advertising, especially employment.

According to the current situation of Iran and economic sanctions against Iran which have created the critical and special situation for the country, this study intended to highlight the role of government, industry, and the resistive economy on people's attitudes and consequently their effect on purchasing Iranian brand goods to provide a basis for managing the importation of foreign products, as well as assisting managers and producers in making correct decisions in this sector.

\section{The Literature Review}

\section{Government}

One of the most important issues in each system is explaining the role of government in economic activities. Government intervention in the economy takes different forms such as direct production, subsidies and pricing of products, and even monitoring the fluctuations of supply and demand. In addition to critical tasks of monitoring, government should conduct and support the private sector and business as well as providing a platform for the development of economic activity, particularly in small and medium industries. The government should create an environment of stability, keep the inflation and interest rates down, and it should try to ensure access to financial resources and develop financial resources needed in small industries such as venturing capital. Governments should empower banks to make loan and encourage the financial system to create new ways of making loan and establishing small businesses. When we look at the pace of employment growth in many developed and developing countries, we observe a very strong role for small firms and $70 \%$ of net employment growth comes from small firms. For example, in Australia, $75 \%$ of all businesses are small businesses and two-thirds of private sector employment is in the small industry. Finally, it must be emphasized that the role of government in this field is important but what the government should only do, is the ensuring a stable economic environment and also facilitation of business growth. This is not the government's job to determine what part should grow small businesses, but it is the markets' task on the basis of market demand.

By opening local markets to imports, government makes the country more vulnerable to fluctuations in the national economy caused by international economic sanctions; therefore, the government should have a careful planning for importing and prevent the importation of unnecessary and luxury goods, too. In general, the government has an important role in economic and social development. To produce and deliver goods and services, a strong government regulations and institutions are required (Moshtagh, 2013). 


\section{Industry}

One of the important factors for sustainable development is generating revenue, decreasing expenses and employing modern industry and technology. One of the characteristics of modern management principles is taking advantage of different industries to achieve a sustainable development as a sign of a healthy and dynamic economy. Many scholars believe that the history of industrial development is compatible and inseparable. In fact, the sustainable industrial development begins with the formation of a full-fledged industry in all sectors. Industry is the full-length attempt of communities to transform the criteria of shaping an ideal society regarding the implementation of welfare-oriented ideals. It can even be argued that in light of the industry, many human needs are met desirably and by establishing industrial organizations in modern societies, a masterpiece of civil society is obtained.

Home appliance industry is one of the important and essential industries in the country. Due to the Iran's high population and the cultural, social, and economic development process of the families, the home appliance industry has become one of the important industries of the country. This industry is one of the accelerated industrial developments and is an industry which adds value for steel, petrochemical, copper industries, etc.

\section{The Resistive Economy}

The resistive economy is a country's economic approach in some certain circumstances which deals with the production and distribution of special products and also investments for reducing dependence on other countries, especially on hostile countries in critical situations; so that if it could not import the essential products and commodities, thus, by self-sufficiency it can have mass production of intended product.

One of the most important issues in resistive economy is supporting national production which represents three tasks for the government, producer, and people. The way of interaction of these three components impacts it directly and the end result is dependent on the interaction. As much as we encourage people to buy domestic products but the quality of domestic products is low, the people will not be willing to buy domestic products. If a manufacturer is to produce high-quality goods but the government and the banking system do not provide monetary and fiscal services or economic laws makes hard to do business, or people are unwilling to buy domestic products, the result will still be negative. Active and dynamic resistive economy requires strategic planning based on people-based economy by empowering private sector and removing obstacles and difficulties of this sector; so that the private sector as the main driver of economic and industrial growth using its capitals and attracting the private-sector capitals makes an efficient use of human resources and also practices an efficient management, thereby, it plays its role in economic and industrial growth and implement government's development objectives.

One of the most important issues in the realization of resistive economy is the comprehensive support of the elites, so that if they are supported, they can transform technology into commercial activities; because empowering the elite in the industry, trade, and agriculture is a feature of resistive economy and the conditions should be provided so that they can do their job without restriction. To achieve better resistive economy, the government should identify weaknesses and transform it to strengths, stabilize the exchange 
rate, employment, price stability, and reform government structure. Consumption management, contentment, avoidance of luxury, solvent wealth creation, and preference to consume domestic products will make people to be more responsible in implementing this kind of economy.

\section{Attitude}

The term attitude is a common term in social psychology and is of various characteristics. Attitude is a hypothetical construct, because it is not directly visible, but it is visible more in verbal and behavioral statements (Azarbayjani, Salarifar, Abbasi, Kaviani, \& Mousavi Asl, 2006). Experts consider that it is vital to study attitude to understand the social behavior. Attitude determines the behaviors and this assumption implies that by changing attitudes, behaviors can be changed (Karimi, 2000). The economy of a country is established on the basis of some specific attitudes which can act as an engine for economic growth and increasing the prosperity.

\section{Buying Iranian Brand Goods}

One of the main reasons for the backwardness of the national economy is the high dependence on oil imports and culture of consumerism. A country which has low economic growth and low per capita income is no need to import consumable luxury goods. Unfortunately, high advertisement of foreign consumer goods in satellite and local television networks has increased the consumption of luxury and worthless consumer goods (in terms of economic growth) by Iranian consumer. Perhaps one of the worst and most fatal blows to our production and industry is purchasing low-quality foreign goods and services. Since some Iranians consider the foreign goods as high-quality products and also some neighboring countries such as Dubai advertise their products extremely, therefore, these affected psychologically the Iranian purchaser to regard them as high-quality products. When domestic products are designed and manufactured according to customer's need and be advertised well, they can attract more purchaser than foreign goods. In many cases, to compete with foreign low-quality products, domestic producers have their prices set in the range of imported products and this is another reason to promote foreign goods, or worst of all, domestic products introduce their products as foreign brand.

Consumers should be informed that consumption of foreign products is not a personal taste, but it leads to unemployment of young people which consequently results in many problems. Iran's education system should plan to increase students' knowledge of cultural identity and national interests. Unfortunately, many Iranian students' stationeries are imported from abroad. This means that Iranian children learn to use foreign goods from the childhood. Following this, mass media should take further restrictions on advertising foreign goods.

\section{The Reason for Priority of Use of Buying Foreign Goods by Iranian Consumers}

1. The Culture of Third World Countries: One of the most common anti-values among the people of the Third World such as Iran is that foreign goods have higher quality than domestic products. As a result, the imported goods are welcomed more than similar domestic goods in the domestic market. 
2. The Poor Performance of Some Domestic Manufacturers: Attitude and performance in the field of production and supply are some of the main reasons for the tendency of consumers to buy or not to buy the products. A manufacturer that its activities are for profit and do it in a short time period, cannot hope to have a longterm production and sell its products. Also attending more to the customer tastes and producing according to their tastes could be a factor to produce and sell more in the long run.

3. Improper Performance of the Government and the Weakness of the Law: It is clear that there is lack of laws to support domestic production and there is a need to review the rules and regulations and offer some effective solutions to improve the productivity and to support further production.

Consumer's preference to buy domestic products is one of the strong intangible barriers in international trade and its consequences have been studied. Shankarmahesh (2006) confirmed it in a number of countries in 2006. The concept of consumer ethnocentrism introduced by Sharma, Shimp, Shin (1995) was interpreted as a form of subdued economy in the belief that their own group (in-group) is superior to the other groups (out-group). Sharma, Shimp, Shin defined consumer ethnocentrism as correct and ethical beliefs of consumers to buy foreign products (John \& Brady, 2011). Ethnic consumers may believe that buying products from other countries is not appropriate and is unethical. The ethical aspects make consumers to buy domestic products even if in some cases they have lower quality than foreign products.

Shimp and Sharma (1987) explained the following as characteristics of consumer ethnocentrism:

1. Their love and concern for their own country and the fear of losing one's economic interests

2. The willingness to buy foreign products

3. Personal biases against imports

4. The attraction of products is due to price or other characteristics of the product (Mangnale, Potluri, \& Degufu, 2011).

Since buying foreign products hurts the local economy and leads to unemployment, to stop buying foreign products, the general tendency is required by the consumer for domestic products. Empirical studies of Shimp and Sharma (1987) showed a positive relationship between ethnocentrism and consumers' prejudice as well as their tendency to buy local goods and products. In other words, ethnocentrism reflects consumer's preferences for domestic products (Vida \& Fairhurst, 1999). Factors such as age, education, income, and gender (Javalgi, Khare, Gross, \& Scherer, 2005) as well as social and psychological factors such as homeland patriotism and nationalism (Balabanis, Diamantopoulos, Mueller, \& Melewar, 2002; Klein, Ettenson, \& Morris, 1998; Vida \& Fairhurst, 1999) are effective in ethnocentrism. A number of studies in other countries have confirmed the negative impact of consumer ethnocentrism on attitudes towards foreign products. For example, Shimp and Sharma (1987) showed that racism in Detroit, Denver, Los Angeles and North Carolina impacts negatively the buyer's attitude towards foreign products. Netemeyer, Durvasula, and Lichtenstein (1991) showed that American and French consumers had a negative attitude 
toward imports and the relationship between ethnocentrism and consumer attitudes towards foreign products in Japan and Germany were negative (Netemeyer, Durvasula, \& Lichtenstein, 1991). Many variables including the availability of domestic alternative, the type of product, and cultural and historical proximity play some moderating role in the relationship between consumer ethnocentrism and attitudes towards foreign products (John \& Brady, 2011; Saffu, Walker, \& Mazurek, 2010; Netemeyer, Durvasula, \& Lichtenstein, 1991; Nijssen \& Douglas, 2004; Jakubanecs, Supphellen, \& Thorbjørnsen, 2005; Yelkur, Chakrabarty, \& Bandyopadhyay, 2006).

\section{Conceptual model}

According to the theory and the hypothesis, the conceptual model is proposed as follows:

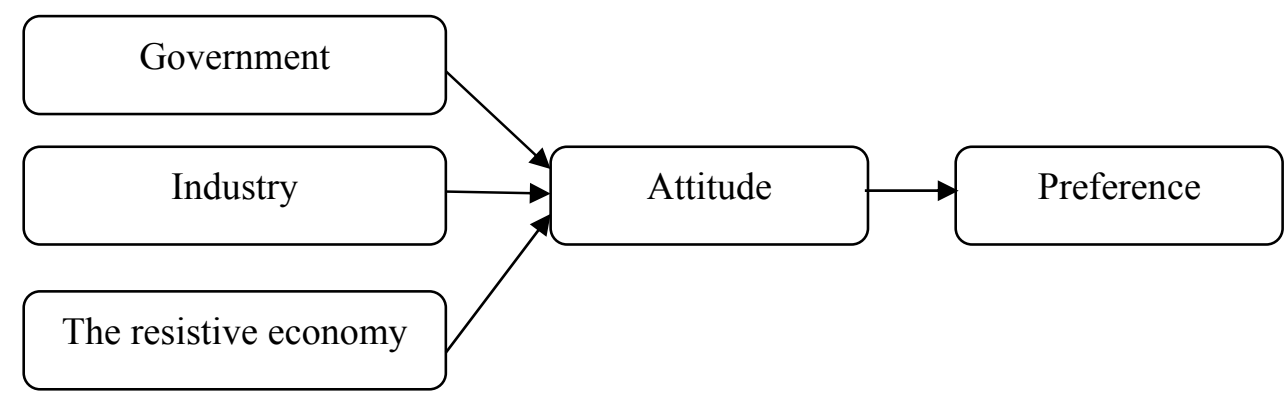

Figure 1. Conceptual model

\section{Hypotheses}

The following hypotheses guided the study:

$\mathbf{H}_{1}$ : The government has a significant impact on attitude.

$\mathbf{H}_{2}$ : Industry has a significant impact on attitude.

$\mathbf{H}_{3}$ : Resistive economy has a significant impact on attitude.

H4: Attitude has a significant impact on Iranian preference.

\section{Method}

\section{Participants}

The study population was the appliance manufacturer participating in Isfahan exhibition in August 2014. This industry was selected as the study population for some reasons: First, many companies have been active in this industry, therefore, there are competitions in the market of this industry. Secondly, it is an industry with various applications that are widely used in household, in offices, and as commercial applications, too. Due to limited availability and time, the sample was selected randomly among appliance manufacturers.

\section{Materials}

In order to collect data, a questionnaire consisting of 32 questions using five-point Likert scale was used. The questionnaire was the same one employed by numerous researchers and its validity and reliability was confirmed. To assess the content validity of the questionnaire, the university experts' ideas were asked.

\section{Data Collection}


This study, in terms of the purpose was applicative. Its method for data collection was descriptive and correlative and, in particular, it was based on structural equation modeling. One hundred questionnaires were distributed among participants and a total of 93 returns were received. To evaluate the reliability of the questionnaire, Cronbach's alpha coefficient was used; the obtained values were higher than the acceptable value of 0.7 . The values of Cronbach's alpha is presented in Table 1.

\section{Data Analysis}

After collecting data and using SmartPLS, the partial least squares were obtained. In the method of least squares PLS, fitting were done in two phases. In the first phase, the external model was tested and in the second phase, the internal model was examined.

\section{Testing the External Model}

Testing the external model includes testing the reliability, validity, and materials of the study. To test the reliability of structures, three indicators of composite reliability, the average variance extracted (AVE), and factor loadings were used (Fornell \& Larcker, 1981). The composite reliability which was higher than 0.7 indicated that the model had a proper value and the criterion for the desirability of AVE was greater than 0.5. After testing the models of measurement and correcting models (deleting the questions with low factor loadings), the results presented in Table 1 indicated that the reliability of the structures was acceptable. To assess the validity of structure, the convergent and divergent validity were employed. The convergent validity evaluated to determine whether the items measure the same concept which was intended. Convergent validity suggested that the values of composite reliability for each structure was greater than the average variance extracted (CR $>A V E)$.

Table 1

Results of Outer Medals

\begin{tabular}{lccc}
\hline Variables & Cronbach's Alpha & AVE & CR \\
\hline Government & 0.69 & 0.53 & 0.81 \\
Industry & 0.66 & 0.58 & 0.80 \\
Culture of Resistive Economy & 0.66 & 0.51 & 0.89 \\
Attitude & 0.67 & 0.51 & 0.80 \\
Buying Iranian Brand & 0.86 & 0.65 & 0.90 \\
\hline
\end{tabular}

To measure the validity of the method of this study, the method used by Fornell and Larcker were employed. They argued that divergent validity is acceptable when the value of AVE for each structure is greater than the common variance between that structure and other structures of the model (i.e., the square of the values of correlation coefficient between the structures) as presented in Table 2 . The model had an acceptable divergent validity when the numbers in the main diagonal were greater than its underlying values (Davari \& Rezazadeh, 2013). 
Table 2

Correlation Matrix

\begin{tabular}{lccccc}
\hline Variables & 1 & 2 & 3 & 4 & 5 \\
\hline 1. Government & 0.72 & & & & \\
2. Industry & 0.20 & 0.72 & & & \\
3. Culture of Resistive Economy & 0.41 & 0.76 & 0.71 & & \\
4. Attitude & 0.30 & 0.44 & 0.45 & 0.76 & 0.45 \\
5. Buying Iranian Brand & 0.31 & 0.59 & 0.68 & 0.45 \\
\hline
\end{tabular}

\section{Testing Internal Model (Structural Model)}

The essential criterion for assessing the structural model is the coefficient of determination (R2) of dependent latent variables. Chin (1998) described the values of R2 0/19,0/33,0/67 as weak, medium, and impressive in PLS path modeling. In this study, the value of R2 for the variables attitude and the purchase of Iranian brand were $0 / 65$ and 0/46, respectively. To test the adequacy of each model of dependent variable, index Q2 can be used. Positive values indicated that the index was good enough (Amani, Khazri Azar, \& Mahmoudi, 2012). If the values for the endogenous variables (dependent) are positive, their average can be used as an indicator for measuring the overall quality of the structural model (Adel, Golamrezazadeh, \& Ghanavati, 2012). The Q2 values obtained for the dependent variables of purchase of Iranian brand and attitude were $0 / 32$ and $0 / 28$, respectively and all of which were positive, and average Q2 was equal to 0.3 indicating the good adequacy of the model.

\section{The Overall Fitting of the Model}

To fit the model in PLS, the GOF index was used. The index values were between 0 and 1 , and the values closer to 1 indicated a better quality for the model. For this study, the amount of which was 0.55 indicated a strong fitness of the model.

\section{Hypothesis Testing}

To test the hypothesis, the path coefficient and the t-test were used. To determine the strength of the relationship between two variables, the path coefficient as the standardized beta coefficients interpreted in OLS regression was used. To determine the significance of the relationship, the values of $t$ (t-value) in the Smart PLS was used as presented in Table 3.

Table 3

Results of Hypothesis Tests

\begin{tabular}{ccccc}
\hline Hypotheses & $\mathrm{t}$ & $\beta$ & Path & Result \\
\hline $\mathrm{H}_{1}$ & Government Attitude & 0.25 & 4.75 & Significant \\
$\mathrm{H}_{2}$ & Industry Attitude & 0.15 & 2.01 & Significant \\
$\mathrm{H}_{3}$ & The Attitude of Resistive Economy & 0.67 & 11.12 & Significant \\
$\mathrm{H}_{4}$ & The Attitude of Buying Iranian Brand & 0.68 & 15.72 & Significant \\
\hline
\end{tabular}




\section{Conclusion}

The aim of this study was to investigate the role of government, industry, and the resistive economy in the attitude of people to purchase Iranian brand goods. As mentioned in the literature review, the previous research been examined the relationship between government and industry. The relationship of attitude and the purchase of locally manufactured products were also investigated. But according to our study of available literature review, no one has examined the effects of resistive economy on attitude. Given that the topic of resistive economy is a new one and the current situation of Iran has created it, it is justifiable. The obtained results showed that the government, industry, and resistive economy had a positive impact on people's attitudes and on the other hand, attitude had a positive impact on preference of buying Iranian brand. Therefore, it can be concluded that to improve industry and create a culture of buying Iranian goods in the country, it is of prime importance that the government support producers to offer the best product at reasonable prices and be able to compete with similar foreign products. On the other hand, the government should encourage people to buy Iranian goods by creating cultural programs in order to have more prosperous country.

\section{References}

Azar, A., Golamzadeh, R., \& Ghanavati, M. (2012). Path-structural modeling in management: Application of SmartPLS software ( $1^{\text {st }}$ ed.). Tehran: Negah-e Danesh Publication.

Amani, J., Khazri Azar, H., \& Mahmoudi, H. (2012). The introduction of structural equation modeling using partial least squares (PLS-PM) and its application in behavioral research. Journal of Psychological Science, 1, 41-55.

Azarbayejani, M., Salarifar, M., Abbasi, A., Kaviyani, M., \& Mousavi, S. M. (2003). Social psychology and attitude to Islamic sources. Tehran: Negah Danesh Press.

Balabanis, G., Diamantopoulos, A., Mueller, R. D., \& Melewar, T. C. (2001). The impact of nationalism, patriotism and internationalism on consumer ethnocentric tendencies. Journal of International Business Studies, 32, 157-75.

Balabanis, G., Mueller, R., \& Melewar, T. C. (2002). The relationship between consumer ethnocentrism and human values. Journal of Global Marketing, 15(3/4), 7-37.

Chin, W. (1998). Issues and opinion on structural equation modeling. MIS Quarterly, 22(1), 7-16.

Davari, A., \& Rezazadeh, A. (2013). Structural equation modeling using PLS software. Tehran: Jahad Daneshgahi Press.

Deb, M., \& Chaudhuri, H. R. (2012). Assessing the ethnocentric tendencies of different age-cohorts in an emerging market. Journal of Indian Business Research, 4(4), 244-268.

Fornell, C., \& Larcker, D. F. (1981). Evaluating structural equation models with unobservable variables and measurement error. Journal of Marketing Research, 18(1), 39-50.

Jakubanecs, A., Supphellen, M., \& Thorbjørnsen, H. (2005). Slavic brothers or rivals? Effects of consumer ethnocentrism on the trade between Ukraine and Russia. Journal of East-West Business, 10(4), 55-78.

Javalgi, R. G., Khare, V. P., Gross, A. C., \& Scherer, R. F. (2005). An application of the consumer ethnocentrism model to French consumers, International Business Review, 14, 325-44.

John, A. V., \& Brady, M. P. (2011). Consumer ethnocentrism and attitudes toward South African consumables in Mozambiqu. African Journal of Economic and Management Studies, 2(1), 72-93.

Karimi, Y. (2000). Attitudes and attitude change. Tehran: Nashr-e-virayesh Publication.

Klein, J. G., Ettenson, R., \& Morris, M. D. (1998). The animosity model of foreign product purchase: An empirical test in the Peoples' Republic of China. Journal of Marketing, 62, 89-100.

Mangnale, V. S., Potluri, R. M., \& Degufu, H. (2011). A study on ethnocentric tendencies of Ethiopian consumers. Asian Journal of Business Management, 3, 241-250.

Mortazavi, S., Kaffashpur, A., \& Arjmandi Nezhad, A. (2010). Examining the mediating role of patriotism and perception of product quality on intent to purchase imported goods. The Bulletin Administration, 10(2), 109-134. 
Moshtagh, M. (2013). The role of government in the current changing world. Tose-eh Journal, 39, 60-63.

Netemeyer, R. G., Durvasula, S., \& Lichtenstein, D. R. (1991). A cross-national assessment of the reliability and validity of the CETSCALE. Journal of Marketing Research, 28(3), 320-327.

Nijssen, E. J., \& Douglas, S. P. (2004). Examining the animosity model in a country with a high level of foreign trade. International Journal of Research in Marketing, 21, 23-38.

Saffu, K., Walker, J. H., \& Mazurek, M. (2010). The role of consumer ethnocentrism in a buy national campaign in a transitioning country: Some evidence from Slovakia. International Journal of Emerging Markets, 5(2), 203-226.

Shankarmahesh, M. N. (2006). Consumer ethnocentrism: An integrative review of its antecedents and consequences. International Market Review, 23(2), 146-172.

Sharma, S., Shimp, T., \& Shin, J. (1995). Consumer ethnocentrism: a test of antecedents and moderators. Journal of the Academy of Marketing Science, 23(1), 26-37.

Shimp, T. A., \& Sharma, S. (1987). Consumer ethnocentrism: Construction and validation of the CETSCALE. Journal of Marketing Research, 23, $280-289$.

Vida, I., \& Fairhurst, A. (1999). Factors underlying the phenomenon of consumer ethnocentricity: Evidence from four Central European countries. International Review of Retail, Distribution \& Consumer Research, 9(4), 321-337.

Yelkur, R., Chakrabarty, S., \& Bandyopadhyay, S. (2006). Ethnocentrism and buying intentions: Does economic development matter? Marketing Management Journal, 16(1), 26-37. 